\section{Tap latent source of frugal cancer ideas}

Richard Sullivan and colleagues propose ways to improve cancer care globally (Nature 549, 325$328 ; 2017)$. For lower-income countries, we suggest that local measures could contribute if they were promoted and developed globally with the help of highincome countries.

'Frugal innovation' in medicine in low-resource settings can suggest cost-effective strategies that are adapted to local constraints to meet an area's needs (see go.nature.com/2hqsyqz). Clinical trials funded by wealthier nations could test the repurposing of inexpensive drugs, such as statins and aspirin, for cancer care (F. Bertolini et al. Nature Rev. Clin. Oncol. 12, 732-742; 2015). This would help to build medical infrastructure in poorer countries.

Clinicians in low-to-middleincome countries have generated data to support drug repurposing, for example using the $\beta$-blocker propranolol to treat blood-vessel cancer (angiosarcoma; see E. Pasquier et al. EBioMedicine 6, 87-95; 2016). High-income nations should show much greater interest in such findings, especially in view of the financial burden of cancer treatment. By investing in co-development, they can help to ensure that care is effective, affordable and equitable globally.

Gauthier Bouche* Anticancer

Fund, Brussels, Belgium.

gauthier.bouche@

anticancerfund.org

${ }^{*}$ On behalf of 4 correspondents (see go.nature.com/2hoh7ch for full list).

\section{Risk assessments face legal scrutiny}

Scientific risk assessments of natural hazards are increasingly subjected to legal scrutiny, given the costly damage of such events (see, for example, Nature 548, 508-509; 2017). The reputations of the scientists, civil-protection managers and politicians tasked with reducing societal risk are on the line should these assessments prove inadequate. The prospect of litigation should help to foster better mitigation practices.

The 2014 eruption of Mount Ontake in Japan killed at least 58 people (see Nature http:// doi.org/cdwp; 2014). Civil claims by bereaved families against Japan's Meteorological Agency and the Nagano prefecture government are ongoing. Unlike the legal proceedings against scientists and government officials following the 2009 earthquake in L'Aquila, Italy (see Nature 477, 264-269; 2011), these claims are not criminal prosecutions. They are for monetary compensation from government entities, similar to the successful 2013 civil claims in Chile after a tsunami in 2010 (R. J. Bretton et al. J. Appl. Volcanol. 4, 18; 2015).

As claimants test the timeline of circumstances leading up to such disasters, scientific records and legal duties of care will be subject to intense scrutiny from peers, lawyers and the media. Earth scientists must confront these pressures with rigorous data monitoring, analysis and interpretations, combined with accurate public communication of any scientific uncertainties.

Richard Bretton, Willy Aspinall University of Bristol, UK. richard.bretton@bristol.ac.uk

\section{Avoid glib terms of development status}

I suggest that the description of countries as 'developing' or 'developed' should be used with caution - or not at all - in the scientific literature. These categorizations are largely subjective, as shown by their controversial and inconsistent usage among global organizations, which have to navigate substantial geopolitical and cultural shifts.
Bodies such as the United Nations, the International Monetary Fund, the Organization for Economic Co-operation and Development and the World Bank classify countries according to their own criteria. Consequently, the number of nations listed as 'developing' by these agencies varies from 184 (go. nature.com/2hkunbv) to 152 (go.nature.com/2ygmatu), 169 (go.nature.com/2yuxd8k) and down to 47 (go.nature. com/2g8tjdv), respectively.

Indices to justify the division - such as education, life expectancy, infant mortality, public health, personal income and poverty levels - can vary within countries and between them, irrespective of their 'development' status. As the $\mathrm{UN}$ and its agencies strive to agree on terminology with representatives of more than 190 countries, we would do well to remember that the designations 'developed, 'less developed' and 'developing' can be used for statistical convenience - but do not reflect a consistent judgement about a country's developmental status.

Khaled Moustafa National Conservatory of Arts and Crafts (CNAM), Paris, France. khaled.moustafa@gmail.com

\section{Does the brain control foraging?}

The quest of the International Brain Lab (IBL) to determine the role of the brain in foraging behaviour (Nature 549, 319320 ; 2017) follows centuries of testing the outcome of different brain manipulations. Those experiments failed to link correlations with causality (see P. Södersten et al. Med. Hypotheses 77, 371-373; 2011).

The brain might instead act as a mediator between controlling factors in the environment and behavioural output. Perhaps, like evolution, it functions as a tinkerer, equipped with a range of signalling or other mechanisms that allow adaptation (see F. Jacob Science 196, 1161$1166 ; 1977)$.

Life would be more enjoyable if so, because the IBL's proposed model of a brain that integrates information and makes moment-to-moment decisions would otherwise leave us with nothing to do.

Per Södersten Karolinska Institute, Huddinge, Sweden. per.sodersten@ki.se

\section{Research that isn't read doesn't exist}

David Moher and colleagues underline how harmful predatory journals are in medicine and related fields (Nature 549, 23-25; 2017). In other research areas that are less well funded, such as my own field of palaeontology, my hunch is that these journals are irrelevant.

Like any other academic, I receive e-mails trying to entice me to publish in the New Journal of Dodgy Fossil Research or similar, but I suspect that - at best - these journals receive papers mainly from fringe researchers who are struggling to get their weak results published. I doubt whether anyone actually reads those articles. And if research isn't read, it doesn't exist.

Stephen K. Donovan Naturalis Biodiversity Center, Leiden, the Netherlands. steve.donovan@naturalis.nl

CONTRIBUTIONS

Correspondence may be sent to correspondence@ nature.com after consulting the author guidelines at http://go.nature.com/ cmchno. Alternatively, readers may comment online: www.nature.com/ nature. 